\title{
MÚSICA CUBANA COM SOTAQUE BRASILEIRO: ENTRECRUZAMENTOS CULTURAIS NOS ANOS SESSENTA*
}

\author{
Mariana Martins Villaça**
}

\begin{abstract}
RESUMO
Este artigo enfoca a Nova Trova cubana, movimento musical emergente no final dos anos sessenta, responsável pela renovação da canção popular nesse país, ao combinar inovações estéticas e engajamento político. Analisamos o contexto político-cultural da época e o processo de constituição desse movimento a partir da formação do Grupo de Experimentación Sonora. Discutimos também as semelhanças entre a Nova Trova e o Tropicalismo, uma das principais referências estéticas do movimento cubano.
\end{abstract}

Palavras-chave: música cubana, Nova Trova, Tropicalismo.

\begin{abstract}
This article focuses the Nova Trova, musical movement from the late sixties that renewed the popular music in Cuba. According to my point of view, this movements try to mix aesthetic innovations with political compromise. I analyze its historical proccess, the political and cultural context and the aesthetic references, since the origin of the Grupo de Experimentación Sonora. I discuss, indeed, the similarity between Nova Trova and Tropicalismo, one of the most important references to the Cuban movement.
\end{abstract}

Key-words: Cuban music, Nova Trova, Tropicalismo.

* O presente artigo é um desdobramento da dissertação de Mestrado Tropicalismo (19671969) e Grupo de Experimentación Sonora (1969-1972): engajamento e experimentalismo na canção popular, no Brasil e em Cuba, orientada pela Professora Doutora Maria Helena Capelato e defendida em 1 de dezembro de 2000. A pesquisa contou com o apoio financeiro da Fapesp.

** Mestre em História pela FFLCH - Universidade de São Paulo. 
Diferentemente dos dias de hoje, quando a expressão música cubana é quase imediatamente associada ao grupo de simpáticos velhinhos "revelados" ao mundo pelas câmaras de Win Wenders e os microfones de Ry Cooder (referimo-nos à banda Buena Vista Social Club, amplamente difundida desde 1999, no Brasil, através do filme e dos CDs homônimos), na década de oitenta não encontravam-se tão próximos do conhecimento e do gosto do grande público os tradicionais boleros, guajiras e sones interpretados com maestria por essa competentíssima velha guarda.

Há cerca de vinte anos atrás, a chamada "Nova Trova" era o movimento musical cubano mais conhecido internacionalmente no âmbito da canção popular e tinha em Silvio Rodríguez e Pablo Milanés seus principais representantes. O tipo de canção difundido por esse movimento consistia num amálgama de gêneros do repertório popular tradicional (freqüente, hoje, nas gravações do Buena Vista) fundido a estilos variados, como a canção de protesto latino-americana, a música pop, os arranjos orquestrais dos Beatles e os experimentalismos sonoros da "música nova", a vanguarda da música erudita da época. Sobressaíam as letras de caráter extremamente lírico ou explicitamente político em canções que se tornaram conhecidas pelo público brasileiro através de gravações de Chico Buarque e Milton Nascimento. ${ }^{1}$

O que pouca gente sabia - e sabe, hoje em dia - é que, na origem desse movimento emblemático da cultura cubana produzida após a Revolução (1959), a música popular brasileira exerceu influência extremamente significativa.

Provavelmente não haveria a Nova Trova e sua estética cosmopolita, caracterizada pela fusão de múltiplos elementos musicais, se Alfredo Guevara, diretor do Instituto Cubano de Arte e Indústria Cinematográficos e uma espécie de "agenciador" da cultura cubana a partir dos anos 60, não tivesse feito uma viagem ao Brasil $^{2}$ em 1968. Durante essa viagem, Guevara

1 "Pequena Serenata Diurna", de Silvio Rodríguez, e "De que callada manera", de Pablo Milanés/Nicolás Guillén, foram gravadas por Chico Buarque. Milton Nascimento gravou "Yolanda" e "Canción por la unidad latinoamericana", de Pablo Milanés, e "Sueño con Serpientes", de Silvio Rodríguez.

2 Guevara viaja a convite da Unesco para participar, no Rio de Janeiro, do Seminário "Nuevo Cine Latinoamericano". Há controvérsias a respeito da data da realização dessa viagem que, ao que indicam as fontes, deu-se em junho de 1968. 
tomou contato com a MPB, seus ídolos, festivais e programas; viu as platéias entusiasmadas e participativas, os filmes nacionais musicados por grandes compositores populares e sonhou para a música cubana um fenômeno semelhante. O envolvimento da juventude brasileira com a música popular nacional, que tanto impressionara Guevara, podia ser percebido através da franca expansão da indústria fonográfica, dos altos índices de audiência das apresentações televisivas (lembremos a popularidade dos Festivais de Música Popular Brasileira da TV Record e dos programas musicais semanais produzidos por diversas emissoras) e da incidência da música popular no Cinema Novo, movimento conhecido de longa data pelo diretor cubano, que desde o início da década mantinha correspondência freqüente com Glauber Rocha.

Cuba encontrava-se, nesse período, numa fase crucial de transformações no meio cultural, pois buscava, desde a decisão de Fidel Castro em ingressar no bloco socialista, em 1961, a definição e o emprego de uma política cultural baseada nos preceitos do realismo socialista soviético. Apesar da inexistência de uma política cultural oficialmente explícita, desde a publicação de "Palabras a los intelectuales", um categórico discurso pronunciado por Fidel Castro em 1961, algumas diretrizes vinham sendo estabelecidas para o meio artístico, todas condizentes com a máxima "Dentro de la Revolución, tudo, contra la revolución, ningún derecho", de clara inspiração leninista. ${ }^{3}$

Inaugurou-se, a exemplo da experiência soviética, um processo de instituição de uma política cultural marcada por ações que visavam promover a centralização e o corporativismo no meio artístico. Institutos e organizações como o Icaic (1959), o Instituto de Derechos Musicales (1960), o Instituto Cubano de Radiodifusión - ICR (1962), o Movimiento de Artistas Aficcionados (1961) e a EGREM - Empresa de Gravaciones Musicales (1964) foram submetidos ao Conselho Nacional de Cultura e, a partir de 1965, ao Partido Comunista Cubano.

3 Tratando especificamente da relação entre os escritores e o partido comunista, Lênin afirmou: "Cada um é livre para escrever e dizer o que bem lhe agrade, sem a menor limitação. Mas toda associação livre (incluído o partido) é livre também para afastar os seus membros que se servem da bandeira do partido para pregar idéias contrárias a ele". Apud STRADA, V. Da revolução cultural ao realismo socialista. In: HOBSBAWM, J. E. História do marxismo. Rio de Janeiro: Paz e Terra, 1987. p. 115. Volume 9. 
Os incentivos do Estado ao meio musical recaíram sobre a produção de hinos e marchas que favorecessem a propaganda política e contribuíssem para manter aceso o entusiasmo da população pelos ideais revolucionários. $\mathrm{O}$ sistema de difusão privilegiava, dessa forma, as canções de conteúdo patriótico condizente com campanhas e mobilizações de caráter ideológico ou os tradicionais gêneros nacionais, preferencialmente a guaracha, o danzón, o bolero, o son e a trova, em detrimento dos demais gêneros que haviam sido "desvirtuados pelo mercado norte-americano": caso da rumba, do chá-cháchá , do mambo e outros gêneros dançantes, que tornaram-se moda a partir dos anos 50 e tiveram algumas de suas características adaptadas àquele público. ${ }^{4}$ Assim, nesse período proliferaram, na música popular cubana, os grupos folclóricos, as agremiações de "trovadores" e "soneros", os "combos"5 e talentos individuais ligados principalmente ao bolero cubano, aceito como "tradição nacional", e ao fílin, um estilo de canção romântica ou "bolero moderno" que vinha se consolidando desde a década de 50.

Dentro dessa perspectiva de valorização do nacional e considerando o peso político-ideológico que o Estado lhe conferia, passou a haver a necessidade da formalização de um modelo de arte ideal. Diante disso, intelectuais ligados ao governo buscaram, em artigos e ensaios, adaptar os princípios do realismo socialista soviético à realidade cubana, na tentativa de sistematizar um modelo de "arte da Revolução". Baseados principalmente em autores russos e em suas leituras do marxismo, aproximaram-se de uma concepção de arte por eles definida como sendo a inter-relação entre a função, a forma e o conteúdo, subordinada às condições sociais e políticas da realidade cubana.

O maestro e musicólogo cubano José Ardévol, em 1960, elaborou uma relação de metas, sob o título "La música y su orientación en el presente

4 Tal adaptação pode ser verificada, por exemplo, através das gravações de sucessos caribenhos/latino-americanos por cantores consagrados como Nat King Cole ou nas inúmeras gravações de rumbas, sambas e mambos estilizados ao gosto dos grandes musicais da Broadway, interpretados por Carmen Miranda.

5 Trovadores, em termos gerais, são intérpretes de música popular cubana que, acompanhados por violão, cantam e improvisam sobre temas relacionados ao cotidiano. Soneros são intérpretes do son, um gênero vocal/instrumental popular e bailável, que deu origem à salsa. O son é executado geralmente pela formação tres-violão-marímbula-guiro-bongô-claves-maracas (admitindo inúmeras variações) e caracterizado pela polirritmia. Combos são bandas multinstrumentais que interpretam gêneros variados. Ver mais sobre o assunto em OROVIO, H. Diccionário de la música cubana. La Habana: Letras Cubanas, 1992. 
cubano", que procurava instruir o músico de forma que este acompanhasse, com sua produção, o momento revolucionário. Para tanto, estabelecia:

- valorização da tradição em detrimento do "cosmopolitismo desfigurador";

- combate aos músicos contra-revolucionários através da Unión Sindical de los Músicos, partindo do princípio de que deveria ser abolido todo o resíduo da tese da neutralidade no meio artístico;

- divulgação ampla de música cubana através de programas oficiais. $^{6}$

Além disso, para que suas músicas se adequassem aos parâmetros desejados do realismo socialista, o compositor deveria observar os seguintes aspectos: as obras deveriam refletir a vida, os sentimentos e problemas da massa; assimilar e divulgar os valores culturais dos outros povos latinoamericanos, lidar com critérios contrários aos das tendências culturais da elite; demonstrar conhecimento da tradição musical nacional e contribuir para a afirmação da independência cultural cubana. Dessa forma, o texto indicava o papel de educador que deveria ser assumido pelo músico, através da adoção de certas práticas, como a de estudar o marxismo e esforçarse para se comunicar bem com o público, inclusive com o público infantil, evitando, nesse sentido, qualquer "ambigüidade literária" em suas canções.?

Pronunciamentos de Fidel e Che Guevara, ao longo da década de sessenta, convocavam artistas e intelectuais a se converterem em exemplos de "homens novos" - termo usado por José Martí para prescrever o ideal de homem voluntarioso, solidário, militante disposto a qualquer sacrifício, consciente politicamente de seu papel de cidadão e, principalmente, de seu compromisso com a manutenção das conquistas obtidas com a revolução. O governo passou então a encampar a "reconstrução da sociedade cubana" conclamando cada trabalhador a se tornar um "guerrilheiro heróico" no cumprimento de suas tarefas, conforme anunciara Che Guevara: "En este

6 ARDÉVOL, J. La música y su orientación en el presente cubano In: ARDÉVOL, J. Música y revolución. La Habana: Unión/Uneac, 1966. p. 128.

7 Essas idéias foram endossadas, dez anos mais tarde, na publicação "Movimento de la Nueva Trova en su X Aniversário" - Biblioteca Nacional José Martí, La Habana, 1982 - que ressaltava três conteúdos básicos da canção: objetivo político, qualidade técnica e eficácia expressiva. 
período de construcción del socialismo podemos ver el hombre nuevo que va naciendo. (...) Todavia es preciso acentuar su participación consciente, individual y colectiva, en todos los mecanismos de dirección y producción (...) Así logrará la total conciencia de su ser social...". ${ }^{8}$ Che Guevara conclamava os artistas a abraçarem a missão de formação dos homens novos e pressagiava: "Ya vendrán los revolucionarios que entoen el canto del hombre nuevo con la auténtica voz del pueblo".?

Nesse contexto, alguns músicos que não seguiam à risca tais preceitos - e, dentre eles, Pablo Milanés e Silvio Rodríguez - enfrentavam problemas com o governo e estavam sob suspeita, acusados de assumirem postura contra-revolucionária em suas músicas ou comportamentos. Silvio Rodríguez era suspeito de atividade contra-revolucionária devido, entre outras causas, ao conteúdo ambíguo de suas letras e Pablo Milanés já havia sido punido, nos idos dos anos sessenta, com uma temporada de prestação de serviços comunitários à Umap - Unidades Militares de Ayuda a la Producción -, a fim de se regenerar de uma suposta "conduta imprópria", uma vez que o objetivo dessas Unidades era "rehabilitar y reeducar a aquellos grupos de la sociedad cuya conducta quedava alienada dentro de los presupuestos éticos dictados por la revolución (...); [la Umap] alcanzaría no pocas vezes, bajo una buena dosis de prejuícios, a determinados sectores sociales de entre los que el medio artístico se haría centro en más de una ocasión". ${ }^{10}$

No caso de Silvio Rodríguez, além da ambigüidade das letras, consideradas pouco didáticas e quase "contra-revolucionárias", contribuía para a suspeita que o envolvia sua experiência como apresentador de um programa musical de TV em 1967. Esse programa, denominado "Mientras

8 GUEVARA, C. O socialismo e o homem em Cuba [Montevidéu, março/1965]. In: ERNESTO Che Guevara: política e ideologia. La Habana: Editorial de Ciencias Sociales, 1990. p. 242-244.

9 Ibid., p. 248.

10 DÍAZ, C. Pablo Milanés: con luz propria. La Habana: [s. n., 19-]. Arquivo pessoal de Rosa Cristina Baéz - La Habana, Biblioteca Nacional José Martí. Presume-se que Pablo Milanés tenha estado na Umap da Província de Camaguey em junho de 1966. Essa reprimenda a Pablo é mencionada rapidamente numa cena do filme Fresa y Chocolate (Morango e Chocolate), do diretor Tomás Gutierrez Alea (Icaic, 1995). Guillermo Cabrera Infante tece alguns comentários sobre a Umap em seu livro Mea Cuba. São Paulo: Cia. das Letras, 1996; descrevendo essas unidades como "campos de concentração camuflados para homossexuais e outros trangressores". p. 94; 397. 
Tanto", ${ }_{11}^{11}$ permanecera apenas sete meses no ar devido à desconfiança da direção do ICR, Instituto Cubano de Radiodifusão, em relação ao grau de comprometimento político do apresentador e à reprovação de sua imagem nada convencional para os padrões televisivos predominantes (cabelos compridos, roupas e botas surradas).

Apesar dessas tensões, o clima nas instituições estatais que polarizavam a atividade cultural era de otimismo: o governo revolucionário se fortalecera com o apoio da URSS e empenhava-se em mostrar ao mundo as conquistas sociais e políticas empreendidas em Cuba. Incentivar as manifestações artísticas nacionais e o engajamento da juventude nos princípios revolucionários eram metas almejadas por todos os setores da cultura, dentre os quais o cinema vinha merecendo especial atenção por ser um meio privilegiado de propaganda ideológica, dentro e fora do país.

Assim, entusiasmado pela idéia de repetir em Cuba o sucesso de público que exibia a música popular brasileira e interessado em melhorar a qualidade das trilhas sonoras dos filmes do Icaic, que já ganhavam considerável destaque em festivais internacionais, Alfredo Guevara desenvolveu o projeto de formação de um Grupo de Experimentação Sonora $-G$. E. S.

Efetivado o projeto, o Grupo fundado por Guevara, filiado ao Icaic e dirigido pelo maestro Leo Brouwer, aglutinou jovens talentos da música cubana, ${ }^{12}$ submetidos a aulas práticas e teóricas para que desenvolvessem amplamente suas potencialidades, além de aprender a fazer "música para cinema". Ao espelhar-se no cenário da MPB, Guevara procurava

11 O programa dominical, cujo título fôra emprestado de uma canção de Silvio, que abria e encerrava o mesmo, tinha roteiro do poeta Victor Casaus e direção de Eduardo Moya. Além de divulgar suas canções, o apresentador fazia entrevistas com três convidados a cada programa. Estreou em setembro de 1967 e durou até abril de 1968, terminando após um episódio polêmico em que Silvio, provocativamente, desprezou um trono existente no cenário e se sentou numa cadeira comum (ato interpretado como possível crítica ao governo).

12 Silvio Rodríguez, Pablo Milanés, Noel Nicola, Martín Rojas, Eduardo Ramos, Pablo Menendéz, Emiliano Salvador, Leonardo Acosta, Sara González e Sérgio Vitier são alguns dos jovens talentos que passaram pelo G.E.S. em seus primeiros anos. A ficha divulgada dos integrantes do Grupo, datada de 1972, é a seguinte: Carlos Aberhoff - sax, flauta; Eduardo Ramos - baixo, guitarra, violão; Sergio Vitier instrumentos de corda; Silvio Rodríguez - violão; Emiliano Salvador - teclado, bateria, percussão; Genaro Garcia Caturla - flauta; Leo Pimentel - percussão, violão; Pablo Menendez - guitarra, harmônica, trombone; Pablo Milanés - vocal, violão; Noel Nicola - vocal, violão; Leo Brouwer - direção musical. Parte técnica: Jeronimo Labrado, José Borras e Ricardo Iztueta. Produção: Lidia Herrero. 
garantir aos músicos, através do cinema, um maior espaço na mídia (naquele momento negado pelo rádio e pela televisão por motivos políticos) e uma vitrine permanente para seus trabalhos, por meio das freqüentes exibições dos filmes e documentários musicados e das apresentações públicas regulares na Cinemateca do Instituto.

Silvio Rodríguez, Pablo Milanés e Noel Nicola foram convidados, em abril de 1969, a integrar o recém-criado G.E.S., e passaram a estudar música e a compor trilhas sonoras coletivamente. Para além dos limites da música para cinema, os músicos do G.E.S. produziram letras ricas em metáforas, melodias que incorporavam timbres, dissonâncias e encadeamentos pouco convencionais, além de misturarem instrumentos e gêneros da música tradicional. O conjunto desses procedimentos deu o tom experimental do grupo, condizente com a orientação estética de Leo Brouwer, que, até 1973, produziu mais de 120 orquestrações para trilhas sonoras. ${ }^{13}$ Segundo o maestro, seu principal objetivo, na época, era "el estudio-investigacióndesarrollo-creación del problema musical, no sólo insertado en el cine, sino también y fundamentalmente, como arte-música per se."14 $\mathrm{O}$ estudo programado por Brouwer consistia em audições dirigidas, seguidas de análise estética e exercícios de composição que tinham como objetivo último a criação de trilhas sonoras originais, que não reiterassem, simplesmente, a "mensagem" transmitida pela imagem.

Os primeiros anos de atividade do G.E.S. (principalmente os anos de 1969 a 1972) foram particularmente interessantes, pois essa foi a fase de maior experimentalismo. Nesse período de investigação e formação, os músicos aprenderam noções de linguagem cinematográfica e princípios teóricos de harmonia, arranjo, composição e toda a bagagem teórico-musical básica. ${ }^{15}$ A produtividade desses anos se deveu muito à ousadia de Brouwer, que procurou introduzir a utilização e a pesquisa das formas abertas nas

13 Em 1973, Eduardo Ramos assumiu a direção e inaugurou um período menos experimental, sem a presença constante de Silvio Rodríguez e Pablo Milanés, produzindo arranjos com menor utilização do violão e da flauta, instrumentos que marcaram o estilo dos primeiros anos.

14 ACOSTA, L. La música, el cine y la experiencia cubana. Cine Cubano, n. 95, p. 72-86.

15 Os cursos tiveram duração aproximada de um ano e meio e foram ministrados pelos seguintes professores: Juan Elósegui (solfejo); Frederico Smith (harmonia); Jerónimo Labrada (eletroacústica) e Leo Brouwer (análise, orquestração e estética musical). 
"linhas de estudo" do grupo, visando apreender e explorar o que era novidade em Cuba: a música dos Beatles, a música brasileira, o jazz moderno, as músicas aleatória e serial, os recursos eletrônicos, enfim, tudo que se apresentasse como "moderno" ou inusitado em relação aos padrões da música nacional. As linhas temáticas de estudo eram as seguintes: a) música pop; b) elementos essenciais da música cubana; c) a canção atual e sua força de comunicação social; d) o fenômeno Beatles; e) a relação musical entre Brasil e Cuba; f) formas de sonoridade atuais; g) a importância da arte transcendente; h) a importância da arte momentânea; i) a experimentação eletrônica aplicada à música popular; j) o jazz; e k) a arte "aberta" e o happening. ${ }^{16}$

Noel Nicola e Silvio Rodríguez chamaram a atenção para a dificuldade da difusão e a incompreensão sofrida no início: " a veces transcurrían meses y meses en que la Nueva Trova era radiada sólo en ocasiones de fechas patrióticas o luctuosas". ${ }^{17}$ " (...) hicemos las primeras canciones autocríticas en la sociedad revolucionária y aquella novedad no fue ben vista por algunos; tanto que a veces las canciones - y con ellas los cantantes - eran interpretadas como contra la Revolución". ${ }^{18}$ Sediando e mantendo o Grupo até 1976, o Icaic garantiu uma divulgação suficientemente eficaz especialmente junto ao meio universitário - do trabalho de seus integrantes. As já mencionadas dificuldades de gravação e difusão se refletiram na data do primeiro LP: 1973.

Apesar disso, as apresentações patrocinadas pelo Instituto e o reconhecimento, pelo público, das vozes dos cantores nas trilhas sonoras de filmes exibidos por todo o país popularizaram o Grupo. O sucesso crescente fez com que o governo reavaliasse as críticas direcionadas ao trabalho de Silvio Rodríguez - o mais controvertido dos compositores do G.E.S. - e passasse a apoiar abertamente o Grupo, a essas alturas já reconhecido como um movimento inovador da canção cubana e considerado responsável pelo surgimento de um novo gênero: a Nova Trova.

16 BROWER, L. La música en el cine cubano: un año de experimentación. Cine Cubano, n. 63, p. 104, set./nov. 1970.

17 NICOLA, N. Por qué la Nueva Trova? A 25 años de la fundación del MNT. La Gaceta de Cuba, n. 5, p. 36, set./out. 1997.

18 ENTREVISTA con Silvio Rodríguez. La Gaceta de Cuba, jun. 1989. 
A aceitação desse rótulo (Nova Trova), inicialmente cogitado e questionado, mas logo bem aceito pelos artistas, ${ }^{19}$ veio de encontro à necessidade que tinham os músicos de se incorporarem ao sistema de difusão, enquanto o governo, por sua vez, via solucionado o problema de ter que lidar com uma forma de canção já recebida com simpatia pelo público que não se identificava a nenhuma outra existente, além da oportunidade de transformar aqueles músicos em exemplos de "artistas da revolução" para o povo cubano e para o mundo.

A fundação, em Santiago de Cuba, da Casa de la Trova - uma homenagem aos velhos trovadores, em 28 de julho de 1968 - e a participação dos "novos trovadores" (Pablo Milanés, Silvio Rodríguez e Noel Nicola) no VI Festival Nacional de la Trova, em março de 1969, contribuíram para reforçar a associação da obra desses músicos à tradição popular nacional e consolidar o termo Nova Trova. Assim, a saída para que o governo apoiasse o G. E. S. sem contrariar os princípios da "arte revolucionária" foi encontrada na aceitação deste como um movimento de renovação da música cubana, isto é, um movimento que, apesar de propor inovações, era identificado fundamentalmente como herdeiro da tradição popular, fator que legitimava suas experimentações, numa perspectiva "dialética" muito cara ao discurso revolucionário.

Em 1971 foi realizado o Congreso Nacional de Educación y Cultura, no qual foram estabelecidas rígidas balizas para a produção cultural e, conseqüentemente, para o meio musical. Esse congresso se estabeleceu como um marco do acirramento da intolerância do governo às obras e artistas não declaradamente comprometidos com os "ideais da Revolução". Na Declaração Final desse evento, ficou estabelecido que as criações culturais e artísticas seriam valorizadas em função de sua utilidade para a Revolução, de sua compreensibilidade pelo povo e a experimentação estética seria permitida se estivesse embasada pelo "rigor ideológico y la alta calificación téc-

19 O termo que batizou o movimento inicialmente oscilou entre "trova joven", "joven trova" e "nueva trova" e foi cunhado pela imprensa como forma de designar uma nova expressão musical que, apesar de certas características exóticas, mantinha-se oficialmente ligada à tradição popular dos antigos trovadores rurais, não suscitando dúvidas a respeito de sua legítima identidade cubana. Assim, "trova" remetia à tradição, e "nova" era explicado com o argumento de que somente uma nova linguagem poderia expressar uma música inserida e produzida por um processo revolucionário. NICOLA, N. Por qué la Nueva Trova? A 25 años de la Fundación del MNT. La Gaceta de Cuba, n. 5, p. 34, set./out. 1997. 
nica" condizente com o princípio propagado por Fidel Castro: "no pude haber valor estético sin contenido humano". ${ }^{20}$ As resoluções sobre o meio musical endossaram a valorização das formas nacionais e o desenvolvimento de programas com fins didáticos ou que incentivassem a pesquisa sobre o caráter e a origem da música cubana. ${ }^{21}$

Também durante esse Congresso foram estabelecidas medidas de cunho autoritário sobre o meio artístico: através de um processo conhecido por "Parametraje", artistas que não reunissem os requisitos morais e políticos para serem considerados "revolucionários" (militância política, heterossexualismo, nenhuma produção de teor crítico ao regime castrista etc.) perdiam seus empregos e eram obrigados a prestar serviços nas já mencionadas Umaps - Unidades Militares de Ayuda a la Producción. O homossexualismo passou a ser oficialmente condenado e foram reafirmados alguns princípios condizentes com o já mencionado "realismo socialista cubano".22

Nesse contexto, os músicos da Nova Trova, ligados ao G.E.S., são inseridos pelo Partido Comunista no recém-criado MNT, Movimiento de la Nueva Trova, e lhes são atribuídas metas de caráter político, firmadas em "Encuentros Nacionales de la Nueva Trova" ${ }^{23}$ e encampadas até 1986. Nessa fase, o $M N T$, sigla através da qual o movimento passou a ser conhecido, teve direção da União da Juventude Comunista e assumiu uma estrutura partidária, tornando-se uma agência, no meio artístico, das propostas político-culturais do Estado. A diretoria do $M N T$ atribuiu aos músicos duas missões fundamentais: uma política - o compromisso de conscientizar politicamente a juventude através de cursos e festivais - e outra de caráter pedagógico-cultural - a ampliação do ensino de música (especialmente do

20 PORTUONDO, J. A. Itinerário estético de la Revolución Cubana. La Habana: Letras Cubanas, 1979. p. 49 e 54.

21 Tais resoluções seriam reafirmadas no texto final dos Acuerdos del I Encuentro Nacional de Jóvenes Trovadores. Manzanillo, 3 de dezembro de 1972.

22 Cf.: ARDEVOL, J. Música y revolución. La Habana: Ediciones Unión/UNEAC, 1966 e AGUIRRE, M. Realismo, realismo socialista y la posición cubana. In: ESCALONA, J. F. (Org.). Estética. Selección de lecturas. La Habana: Editorial Pueblo y Educación, 1987.

23 O primeiro encontro ocorreu em 1972 e o segundo, em 1973, ambos na cidade de Manzanillo. Cf.: DECLARACIÓN del Primer Encuentro Nacional de Jóvenes Trovadores. MOVIMIENTO de la Nueva Trova en su X Aniversario. La Habana: Biblioteca Nacional José Martí, 1982. p. 7-13. 
violão e dos gêneros populares) a todos os lugares do país onde houvesse uma sede da União da Juventude Comunista.

$\mathrm{Na}$ "Declaración del Primer Encuentro Nacional de Jóvenes Trovadores", datada de dezembro de 1972, percebemos que, a partir da institucionalização do Movimiento de la Nueva Trova, os músicos tiveram que seguir, agora com um rigor muito maior, os princípios do realismo socialista cubano, como indicavam as orientações dadas aos jovens candidatos a futuros "novos-trovadores": "utilizar lo mejor de la cultura universal (...) siempre con un rigoroso criterio leninista que implica la asimilación crítica del arte"; “(...) debemos estar en guardia no sólo contra expresiones artísticas de abierta condición contrarrevolucionária; sino contra obras que intentan adormecer el gusto popular y deformarlo". ${ }^{24}$

Sílvio Rodríguez e Pablo Milanés, apesar de terem, diversas vezes, assumido atitudes de crítica em relação a certas medidas impostas pelo governo, não ofereceram resistência à oficialização do movimento (talvez vislumbrando as oportunidades que se abririam, com o apoio estatal) e foram convidados a assumir os "cargos" de "embaixadores da música cubana no exterior". Por meio desses cargos simbólicos, os dois músicos realizaram uma série de turnês por países estrategicamente escolhidos ${ }^{25}$ pelo governo.

Nos anos setenta, a imagem da Nova Trova se fixou internacionalmente como "canção de protesto". Isso ocorreu em grande parte devido à política cultural do governo de Fidel Castro, que transformou a Nova Trova no "estilo musical da Revolução". Além disso, foram mais divulgadas para o grande público as canções do movimento cujas letras serviam à conscientização ou homenageavam episódios ou heróis da Revolução (temática predominante em boa parte da produção dos compositores cubanos identificados a essa tendência) do que os experimentalismos realizados pelos musícos no G.E.S. Tais experimentalismos, entretanto, mesmo sob certo disfarce da roupagem política exigida pelo governo, não desapareceram, pelo contrário: fundiram-se às mensagens de conteúdo político, confi-

24 DECLARACIÓN... p. 7-8.

25 Alemanha Oriental (III Festival Internacional de la Canción Política - Berlim), Chile (IV Festival de la Canción Comprometida - Valparaíso), URSS, Espanha e Angola são alguns dos países percorridos pelos músicos cubanos. 
gurando, em Cuba, uma forma muito original de canção de protesto. Vejamos alguns desses elementos de originalidade e sua relação com a música brasileira dos anos sessenta.

\section{Tropicalismo à moda cubana}

A reinvenção de tradições musicais (reaproveitamento de temas, ritmos e sonoridades) foi um procedimento que constou das entrelinhas das propostas do Grupo de Experimentação Sonora, associado por seus integrantes à música brasileira e ao Tropicalismo - ou ao que entendiam por Tropicalismo. Os músicos da Nova Trova consideravam admirável o modo como os compositores brasileiros captavam o folclórico e o tradicional com timbres novos e é curioso observar, em relatos cubanos a respeito da música popular brasileira, análises que ora indiferenciavam as variadas tendências, englobando-as num fictício e abrangente Tropicalismo, ora generalizavam uma corrente "nacionalista", interessada em valorizar o povo e retratar a realidade brasileira (corrente na qual o Tropicalismo também se situaria, segundo essa perspectiva) em oposição às tendências musicais estrangeiras. Isso nos revela que, apesar de os cubanos disporem de razoável quantidade de informação sobre os artistas e os estilos brasileiros, havia muita dificuldade em identificar a diversidade observada. Nesse sentido, Guillermo Villar afirma que, para o processo vivido pelo G.E.S. de busca de sua identidade, foi imprescindível o movimento de aproximação da música brasileira, "con la cual teníamos tantos puntos de contacto, aunque se conocia escasamente". ${ }^{26}$

Silvio Rodríguez declarou-se, na época, admirador dos "tropicalistas" Chico Buarque [sic], Marcos Valle e Gilberto Gil, ressaltando que esse último "fue el primer autor e intérprete brasileño que admiré y segui". ${ }^{27}$

26 VILLAR, G. G.E.S. II. Revolución y Cultura, La Habana, [19-]. Outras visões da música brasileira em Cuba podem ser observadas nos artigos: PERES, M.; LOPES, J. La música popular brasileña. In: ENSAYOS de música lationamericana - seleción del Boletín de Música de la Casa de Las Américas. La Habana: [ s. n.], 1982; PERES, M.; LOPES, J. La Nueva Canción latinoamericana. In: ENSAYOS de música Latinoamericana - selección del Boletín de Música de la Casa de las Américas. La Habana: [s. n.], 1982.

27 ENTREVISTA a Silvio Rodríguez. Juventud Rebelde, La Habana, 13 dec. 1987. 
Caetano Veloso e Chico Buarque (além de Milton Nascimento) eram situados dentre os principais representantes da Nova Canção Latino-americana, ${ }^{28}$ confirmando a indiferenciação feita entre todos esses compositores que, na perspectiva cubana, contribuíram para uma renovação da música brasileira. ${ }^{29}$ Essa generalização, entretanto, não é difícil de ser compreendida se observarmos o que, exatamente, na música popular brasileira, atraía os músicos cubanos. Vejamos:

Leonardo Acosta, ex-instrumentista do G.E.S., analisa a influência da música brasileira sobre os músicos cubanos, afirmando que o grupo almejava uma renovação similar àquela ocorrida em nossa música, a saber, $a$ fusão de uma multiplicidade de gêneros, segundo seu ponto de vista. Para isso, os músicos cubanos dispunham-se a aproveitar tudo que pudesse enriquecer suas composições: jazz, rock, samba, técnicas eletrônicas de gravação, dentre outras referências. ${ }^{30}$

O colombiano Francisco Gutiérrez enfatiza a forma peculiar e sofisticada de protesto que se estabeleceu dentro da MPB e inspirou os músicos cubanos: "Brasil enseña a Silvio e integrantes del movimiento de la Nueva Trova a hablar social y politicamente sin ser directos. De esta forma desarrollan la técnica de composiciones pluritemáticas o sugerentes. Con el paso de los años y las necesidades los trovadores cubanos se especializaron en la melosa y universal temática amorosa para: moderar actitudes, inciativas y pensamientos hostiles; enunciar conducta anti o irrevolucionaria; movilizar; manifestar solidariedad; opinar..." 31

Assim, os músicos cubanos consideraram interessante a música popular brasileira por ser essa esteticamente heterogênea, "moderna" e não linear ou previsível em sua forma de protesto, aspectos que, vistos por esse prisma, representam certa unidade no conjunto dos principais nomes e ten-

28 Cf.: AGUILA, V. Confesiones de Pablo y Silvio. El Caimán Barbudo, n. 179, nov. 1982.

29 Em visita a Cuba, por ocasião do Coloquio Internacional Musicologia y Globalización, realizado pela Casa de las Américas em outubro de 1999, pudemos verificar que ainda é confusa a idéia do que seja o Tropicalismo: o conceito, além de ser usado como sinônimo da MPB dos anos sessenta e setenta, é identificado ao fenômeno, que ocorre já na década de oitenta, de "latinização" dos arranjos da música pop dançante, isto é, à utilização de "roupagens" supostamente tropicais (percussão caribenha, ritmos sincopados etc.) em gravações de bandas pop internacionais.

30 ACOSTA, L. Radiografia del G.E.S. El Caimán Barbudo, La Habana, mar. 1989.

31 GUTIERREZ, F. Silvio Rodriguez, el elegido. Cali: FAID, 1998. p. 116. 
dências que compunham a chamada MPB. Além desses aspectos gerais, outros, mais específicos, são apresentados:

Dentro da proposta metodológica do G.E.S., a justificativa do estudo da MPB aparecia na seguinte afirmação de Leo Brouwer: "Especialmente investigamos la unidad entre lo cubano y lo brasilero, porque contienen los mismos elementos africanos. Con excepción de Brasil y Cuba, la América Latina posee raíces indígenas, por lo tanto nuestra relación (...) no puede ser partiendo del pasado histórico cultural, sino del presente revolucionário". 32

Selando a admiração declarada pelos artistas de ambos países nos anos sessenta, ao longo da década de setenta ocorreram em Cuba alguns shows de músicos brasileiros. Em 1973, no programa impresso do "Concierto Brasil-Cuba", que reuniu o G.E.S. a músicos brasileiros que interpretaram Gilberto Gil, Edu Lobo e Chico Buarque (dentre outros), na Cinemateca do Icaic, havia um pequeno texto justificando o encontro e respondendo à pergunta "por que Brasil?" A justificativa apontava semelhanças entre o samba e a conga, a bossa nova e o tumbao, os compositores Villa-Lobos e Caturla, Carlos Gomes e Gaspar Villate, e, por fim, homenageava Luís Carlos Prestes, Lamarca e Mariguella.

\section{Simetrias sonoras}

É possível estabelecermos certas silmilaridades entre a sonoridade do Tropicalismo e a da Nova Trova, que, como vimos, se aproveita desta para compor sua identidade. Antes, porém, de comentarmos tais semelhanças - e algumas particularidades -, é preciso não perder de vista as muitas diferenças entre os contextos históricos nos quais esses movimentos musicais se gestaram e a singularidade da identidade de cada um (as quais abordamos pormenorizadamente em nossa dissertação de mestrado), sendo nosso

32 PEREIRA, M. En busca del sonido americano. Revista Cuba Internacional, año 4, n. 29, p. 24 , ene. 1972 . 
objetivo apresentar, neste artigo, apenas certos traços estéticos e musicais comuns a partir da constatação da incidência do Tropicalismo na música cubana.

Nesse sentido, partimos da perspectiva de comparação apresentada por Maurice Aymard ao alertar que a validade desse procedimento, para além da identificação das especificidades e semelhanças entre os objetos, está na tarefa de buscar as relações de complementaridade ou de exclusão que as expliquem e as estruturem, uma vez que, segundo o autor, "causas semelhantes não produzem, sempre e sob qualquer circunstância, os mesmos efeitos; e efeitos semelhantes podem, por sua vez, remeter a causas diferentes". ${ }^{33}$ Tendo em vista essa assertiva, façamos um breve apanhado dos elementos sonoros que sobressaem dessa comparação.

No Tropicalismo, as fusões de ritmos, estilos e gêneros são muito freqüentes e consoantes com dois procedimentos bastante usados pelos compositores: a paródia musical (imitação integral ou parcial de determinada obra) e a colagem (somatória ou justaposição de elementos musicais variados) - recursos que lhes permitem rechear as canções de citações melódicas e rítmicas, remetendo o ouvinte, através da reprodução fiel de determinado excerto ou da simples alusão temática, a gêneros diferentes daquele predominante na canção.

Na famosa "geléia geral" tropicalista (expressão da autoria de Décio Pignatari, que batizou uma canção de Gilberto Gil e Torquato Neto sexta faixa do LP Tropicália ${ }^{34}$ - e passou a designar a mistura de gêneros e estilos característica do Tropicalismo) há a predominância de gêneros nacionais, porém, com tratamento "pop", isto é, executados por instrumentos diferentes daqueles característicos.

Analisando as canções da Nova Trova, verificamos que boa parte delas também misturam gêneros e geralmente trazem uma primeira parte "tradicional" (uma melodia em ritmo popular como o son, por exemplo) e uma segunda parte mais ousada, na qual a melodia se transforma num rock

33 AYMARD, M. Histoire et comparaison. In: ATSMA, H.; BURGUIÈRE, A. Marc Bloch aujourd'hui: histoire comparée \& Sciences Sociales. Paris: Ed. de l'École de Hautes Études en Sciences Sociales, 1990. p. 278. Tradução da autora.

34 Essa canção é considerada, por Celso Favaretto, "o interpretante do disco; (...) a matriz que condensa todos os paradigmas redistribuídos na combinatória das outras músicas, da capa e contracapa". Cf. FAVARETTO, C. F. Tropicália: alegoria, alegria. São Paulo: Ateliê, 1996. p. 75. 
ou ganha andamento mais acelerado que o anterior, explorando intensidade, timbres e provocando o efeito de "ponto culminante" da canção. ${ }^{35}$

No conjunto das obras, prevalece o estilo "canção de protesto", que, no caso cubano, tem como principal característica o aproveitamento de gêneros populares com um tratamento musical "moderno" (utilização de instrumentos elétricos, efeitos de estúdio e outras inovações de época) também presente no Tropicalismo.

A "geléia geral" cubana, especialmente se observarmos as canções da Nova Trova produzidas pelos músicos quando estes estavam reunidos no G.E.S., poderia ser decomposta em duas principais vertentes. De um lado, a tradição da música popular cubana (gêneros dançantes como a salsa, o danzón e o son; ou a tradição romântica, da qual o fílin faz parte) e, de outro, a tendência de aproximação ao pop internacional e às principais tendências da época, a saber: o estilo Beatles (mais especificamente os procedimentos da banda, como o aproveitamento sinfônico de melodias modais e cantigas nos arranjos); o rock associado à exploração de timbres elétricos e eletrônicos; o canto quase falado, ao estilo de Bob Dylan; as improvisações inspiradas no free jazz - e conhecidas em Cuba como descargas $;^{36}$ as formas de canção de protesto latino-americanas (com destaque para as obras de compositores consagrados como Victor Jara, Carlos Fuentes, Violeta Parra, Atahualpa Yupanqui, dentre outros) e a MPB, particularmente a batida da Bossa Nova e diversos elementos dos arranjos tropicalistas.

Podemos verificar, portanto, a importância da fusão de gêneros como marca dos dois movimentos e uma forte tendência de releitura das tradições populares somada à incorporação ou reapropriação de elementos da música pop internacional (englobando expressões diversas como o iêiê-iê, a protest song norte-americana e as várias correntes do rock). Justamente por isso, tanto o Tropicalismo como o G.E.S. e a Nova Trova foram

35 A canção Mis 22 años de Pablo Milanés, por muitos musicólogos cubanos considerada uma "precursora da Nova Trova", já traz uma conbinação de fílin - 1. a parte, lenta - e guajira - 2. parte, movida - que ilustra essa tendência.

36 Além das descargas, inúmeros outros elementos e práticas do jazz são frequientes na música cubana, dada a forte tradição jazzística conhecida como afrocuban, consolidada e internacionalizada pelos combos, bandas instrumentais de estilo voltado à improvisação, geralmente compostas pela base saxbateria-contrabaixo, que proliferaram na ilha a partir da década de cinquenta. Cf.: ACOSTA, L. Elige tu, que canto yo. La Habana: Letras Cubanas, 1983. 
alvos de polêmica em relação às possibilidades de classificação de seus estilos de composição e interpretação - musicalmente falando, ora era identificado um gênero (o "gênero tropicalista" ou o "gênero nova-trova"), ora uma forma, uma atitude ou uma estética ${ }^{37}$ - discussão que tem raiz na própria miscelânea ou irregularidade que caracterizaram as produções desses movimentos.

Podemos dizer que os arranjos tropicalistas são geralmente orquestrais e exploram bastante o recurso do "contraste" através de citações melódicas, mudanças de gênero, padrão rítmico e andamento. Os naipes da orquestra são utilizados de maneira a ressaltar esse recurso - em vários casos, sopros e cordas se intercalam, valorizando a exploração timbrística de um mesmo tema melódico, e, em outros tantos, trechos líricos, em que predominam as cordas, contrastam com passagens mais movidas, pontuadas ritmicamente pelos metais, em estilo big band. Também é freqüente a utilização de instrumentos regionais: a formação tradicional do baião (triângulosanfona-zabumba), instrumentos da capoeira (berimbau, agogô, caxixi, tumbadoras) e instrumentos populares de percussão tocados isoladamente (o pandeirinho de Rita Lee, por exemplo, cuja imagem ficou registrada em inúmeras gravações de apresentações na televisão).

A introdução do uso da guitarra elétrica, a propósito, em arranjos de MPB pode ser considerada um marco tropicalista: após o Festival da Record de 1967, no qual se destacaram as canções Domingo no Parque e Alegria, alegria, contabilizamos, no festival do ano seguinte (IV Festival de Música Popular Brasileira), 10 canções, dentre 18, que apresentavam guitarra elétrica em seus arranjos.

Assim, no Tropicalismo, notamos, de maneira geral, arranjos que têm um caráter predominantemente contrapontístico, ou seja, o arranjo "dialoga" com a melodia através de intervenções instrumentais, citações e linhas melódicas independentes que fazem contraponto à linha principal, fornecendo códigos que muitas vezes complementam ou contradizem as idéias que estão sendo cantadas. Nesse aspecto, podemos verificar certo legado da Bossa Nova: a combinação de diferentes linhas melódicas e rítmicas, em

37 Cf. PALMER, M. Del bardo que te canta. La Habana: Letras Cubanas, 1988. p. 13. A autora faz uma interessante discussão dessa polêmica. 
sobreposição ou defasagem, com o objetivo de obter, através do conjunto, determinado efeito. ${ }^{38}$

Os arranjos produzidos pelos músicos da Nova Trova são quase sempre orquestrais, utilizam com destaque o naipe de sopros (principalmente flauta, saxofone e clarinete), que se sobrepõem às cordas, e uma grande variedade de instrumentos de percussão: mesmo quando a música recebe um tratamento de rock, raramente são deixados de lado instrumentos típicos da música cubana, como as claves, as maracas ou o güiro. Esses arranjos geralmente exploram contrastes a partir de mudanças de andamento ou gênero e são feitos para uma formação numerosa de instrumentistas (são raros os arranjos minimalistas), característica peculiar das bandas cubanas após a década de quarenta. Quando não há orquestração, o instrumento principal de acompanhamento é o violão, utilizado quase sempre com a função estrita de acompanhamento simples - exceção feita a algumas canções de Silvio Rodríguez, nas quais a mão direita traz dedilhados mais elaborados que a tradicional forma "rasgueada". Notamos também, com certa freqüência, a formação violão-teclado-baixo-flauta transversalpercussão, considerada bastante ousada para os padrões da época, por utilizar instrumentos elétricos.

Equiparados à inventividade tropicalista, tais arranjos representaram um marco na história da música popular cubana, principalmente pelas orquestrações modernas que empregou. Segundo a musicóloga Clara Díaz, além das influências e da criatividade pessoal de Leo Brouwer (o "Rogério Duprat" da Nova Trova), tais arranjos teriam influência de uma tendência estilística introduzida pelo músico Juan Formell, no final da década de sessenta, ${ }^{39}$ que substituiu o contrabaixo acústico pelo elétrico, o teclado pelo piano e encarregou flauta e violão da condução da linha melódica, atribuindo um caráter mais rítmico às cordas, mudanças que

38 Walter Gacia fez uma esmiuçada análise musical da bossa nova, especialmente da "batida de João Gilberto", explorando suas características e a relação existente entre estas e certos princípios rítmicos, melódicos e harmônicos do samba, do jazz e do samba-canção. Particularmente interessante foi sua constatação de que a bossa nova, mais que inovar ou romper, reelaborou certos elementos já presentes nesses gêneros e estilos que a antecederam ou lhe foram contemporâneos. GARCIA, W. Bim Bom. A contradição sem conflitos em João Gilberto. São Paulo: Paz e Terra, 1999.

39 Formell dirige a Orquestra Revé, em 1967/68 e a banda Los Van Van a partir de 1969. 
conferiram uma sonoridade moderna à orquestração tradicional da música popular cubana. ${ }^{40}$

No que se refere às letras, é possível afirmar que, num plano geral, mais do que tratar os problemas do Brasil numa perspectiva de apelo à transformação, o Tropicalismo os expõe.$^{41}$ Não há a explicitação de uma dada "mensagem", mas não podemos negar que haja um "engajamento", ou seja, um envolvimento e um comprometimento do artista em traduzir e criticar a realidade de seu país. ${ }^{42}$ É dado ao ouvinte a decisão de interpretar o painel construído sob o viés da denúncia ou da celebração e a "chave" para essa escolha é dada pelos elementos essencialmente musicais, particularmente, e pelo diálogo que o arranjo estabelece com a estrutura mais facilmente inteligível da canção (letra, tema, performance, execução).

Já no caso cubano, por se tratarem, quase sempre, de canções que trazem um apelo, uma "mensagem" de conscientização política, a letra é bastante valorizada, organizada de forma estrófica, com a presença de bordões de fácil memorização. Nas trilhas sonoras instrumentais produzidas pelo G.E.S. no Icaic, entretanto, observamos arranjos nos quais verificamos o emprego de procedimentos da música contemporânea (serialismo, atonalismo e polifonia, por exemplo), dado que contrasta com aqueles arranjos modernos, porém menos ousados, das canções de protesto, conferindo à Nova Trova uma pluralidade notável de estilos.

Um último aspecto comparativo merece ser comentado. Em relação às inovações e aos recursos de estúdio utilizados nos arranjos, notamos uma grande incidência de efeitos eletroacústicos que exploram ruídos, remetendo-nos a certo clima "futurista" ou de filme de ficção científica. Há, por exemplo, em gravações dos dois movimentos, sons que sugerem ruídos de um disco voador ou nave espacial, além da utilização do recurso de

40 "Los primeros esfuerzos por renovar nuestra música popular provinieron, a fines de la década de los 60, de la orquesta Van Van de Juan Formell, que introdujo el instrumental electrónico (...) y del G.E.S. del ICAIC, que supo combinar la canción de contenido político y social con orquestraciones modernas y el uso de ritmos cubanos y brasileños, así como elementos del jazz, el rock, la música barroca y otras". ACOSTA, L. Del tambor al sintetizador. La Habana: Letras Cubanas, 1969. p. 62. Cf.: DÍAZ, C. Sobre la guitarra, la voz. La Habana: Letras Cubanas, 1994. p. 214.

41 Cf.: SCHWARZ, R. Cultura e política: 1964-1969. In: SCHWARZ, R. O pai de família e outros estudos. Rio de Janeiro: Paz e Terra, 1978.

42 Cf.: SARTRE, J. P. Que é literatura. São Paulo: Ática, 1993. 
desacelerar a rotação do disco para se obter um efeito semelhante ao da "falta de energia" num aparelho de som ou a uma máquina que vai parando aos poucos.

Ilustrar determinadas passagens das canções como se houvesse uma trilha sonora de fundo para o enredo daquela própria canção é uma prática que se observa tanto em canções tropicalistas como em canções do G.E.S., recheadas de imitações de passarinhos, vento, mar, sinos, sons urbanos, canhões etc. Além disso, foi fartamente usado o recurso das distorções em estúdio: vozes metálicas, timbres distorcidos de instrumentos, pedais, "timbres sujos" da guitarra ou do baixo etc. Isso se explica pela novidade que tais recursos representavam na época e por uma predisposição a aproveitálos ao máximo.

Outras novidades propiciadas pelo desenvolvimento técnico dos estúdios, que ocorreu após a segunda metade da década de sessenta, também foram bastante utilizadas: o efeito de eco (provocado nas vozes ou nos instrumentos), a sobreposição de vozes, os ruídos obtidos por formas inusuais de tocar determinados instrumentos (percussão na caixa do violão, por exemplo), dissonâncias propositais, produzidas a partir da junção de muitos timbres numa "massa sonora", e toda espécie de aproveitamento da voz humana (risada, gemido, suspiro, assobio, grito, tosse etc.). Comparando o conjunto das produções de cada movimento, é possível afirmar que, de um modo geral, foram menos ousados os recursos utilizados pelo G.E.S., em relação aos presentes no Tropicalismo, talvez em função de os estúdios cubanos serem menos equipados que os brasileiros. Esta e outras particularidades também obedecem, além dessa questão prática dos equipamentos, às características da música popular brasileira e da cubana: notamos, por exemplo, que a percussão tem um peso bem maior nos arranjos cubanos que nos brasileiros e, em decorrência disso, os efeitos que a exploram são mais frequientes em Cuba, ao passo que, no Brasil, a ênfase recai sobre a exploração melódica e harmônica. Se compararmos exclusivamente as obras instrumentais, entretanto, veremos mais experimentalismo nas trilhas sonoras cubanas - e isso provavelmente ocorreu devido ao G.E.S. ter contado, dentre seus componentes, com alguns músicos que eram essencialmente instrumentistas (o que não ocorreu com o Tropicalismo) e que se dedicaram à composição de obras desse tipo, além de fazerem o usual acompanhamento. Tais músicos, dirigidos por Brouwer, estavam bastante próximos das últimas tendências da música contemporânea e aproveitavam as 
trilhas sonoras que lhes eram encomendadas para exercitar novos procedimentos, conferindo-lhes a sonoridade vanguardista.

A incorporação desses recursos atendia às tendências da época (modismo incentivado pelas gravadoras), à influência dos Beatles e a um grande e inegável interesse, dos músicos e dos respectivos arranjadores/ maestros, em explorar novos timbres e efeitos, à medida que vivenciavam uma verdadeira febre, no meio popular e no erudito, pela busca do aproveitamento total das possibilidades técnicas e sonoras encampadas pela Nova Música ${ }^{43}$ Assim, características observadas na produção musical de ambos os movimentos, como modulações inesperadas, sensação de "tonalidade flutuante" marcada pelo uso de acordes dissonantes ou imprevistos (principalmente no caso brasileiro), cromatismos e atmosferas modais (principalmente no caso cubano) e outros procedimentos que fugiam ao tratamento harmônico tradicional, acompanhavam as tendências de experimentalismo e a atitude de ruptura com o sistema tonal, em voga no final da década de sessenta.

\section{Considerações Finais}

Por mais imprecisa que possa ter sido a percepção das tendências da música brasileira pelos músicos cubanos nos anos sessenta, esta foi suficiente para que houvesse a constatação de que a originalidade da MPB se assentava em bases ecléticas, para além das "raízes folclóricas" tão celebradas naquela época. A necessidade da assimilação dos mais variados elementos musicais, nacionais e estrangeiros, é vista pelos cubanos como um caminho para a modernização ou renovação da música popular, objetivo que, de certa forma, estava presente nas preocupações dos tropicalistas, que pretenderam, inicialmente, encontrar o chamado "som universal".

43 Como resultado desses anseios comuns, é possível identificar características semelhantes entre a música erudita produzida no Brasil e em Cuba no período estudado, campo pelo qual transitaram os maestros Rogério Duprat, Julio Medaglia e Leo Brouwer. Ver, sobre esse assunto, o artigo de AHARONIÁN, C. El casi regreso de Conrado Silva. Boletín de Música, Casa de las Américas, n. 35, p. 9-12, [19-]. 
Existem várias declarações dos integrantes do Tropicalismo acerca de suas intenções em buscar uma nova sonoridade para a música popular - o chamado som universal que, resumidamente, seria a síntese da combinação entre as características da música pop daquele momento e as tendências (recentes) e referências (tradicionais) da música popular brasileira. Também encontramos no G.E.S. essa mesma disposição. ${ }^{44}$ Nesse sentido, a música popular brasileira, em sua diversidade, oferece aos músicos cubanos um painel do qual extraem não só o produto final (a própria MPB, em toda sua heterogeneidade) como também a leitura do que a eles parecia ser a "receita" da combinação de conteúdo político (o engajamento crítico, poderíamos assim dizer) e forma criativa (sonoridade moderna e original, sem excluir raízes na música nacional e popular).

Em ambos os casos, além de ser uma opção estética, essa postura assumiu um forte caráter ideológico, como veremos logo adiante.

No panorama geral da América Latina, apenas em Cuba e no Brasil detectamos essa preocupação de forma intensa - a saber, a busca de interação e comunicação com a música popular internacional -, uma vez que nos demais movimentos de renovação da canção popular, no âmbito da Nova Canção Latino-americana, como os que são verificados na Argentina, no Uruguai e no Chile, houve muito maior ênfase no resgate do folclore e das tradições indígenas. Nesses países sul-americanos de língua hispânica, a resistência aos regimes militares esteve fortemente relacionada, nas manifestações artísticas em geral e na canção popular (o chamado "nuevo canto"), a temas como a valorização do passado histórico, do indígena ou do camponês explorados, sendo o meio rural cenário constante nas letras e temáticas. Brasil e Cuba têm culturas nas quais a presença do negro é mais visível que a do indígena e nas quais a mistura, o sincretismo, apresenta-se como elemento catalisador da identidade nacional. Tais particularidades já foram comentadas por alguns autores, dentre os quais, Eduardo Carrasco. ${ }^{45}$ Esse musicólogo chileno e integrante do conjunto Quilapayún listou algu-

44 "La base de la experimentación es lo popular, aunque actualmente no se puede hablar en términos de música culta o popular, ambas se mezclan y producen la música universal”. PEREIRA, M. En busca del sonido americano. Revista Cuba Internacional, año 4, n. 29, p. 24, ene. 1972.

45 CARRASCO, E. P. La nueva canción en América Latina. In: MEMÓRIAS del Foro Primer Festival del Nuevo Canto Latinoamericano. Ciudad de México: Unesco/INBA/Casa del las Américas, abr. 1982. p. 13-46. 
mas características que, a seu ver, distinguem a MPB emergente nos anos sessenta da Nova Canção Latino-americana. $\mathrm{O}$ autor chama a tenção para o fato de que essa MPB não surgiu do folclore e sim da música popular brasileira influenciada pela música moderna (sobretudo o jazz); surgiu dentro da música comercial, apropriando-se dos canais de difusão existentes (televisão, por exemplo); assimilou influências estrangeiras sem deixar de ser "típica" [sic]; e, apesar de politizada, não aderiu às formas engajadas, o que lhe permitiu exercer um papel de crítica social sem sectarizar-se. Em sua análise, o autor afirmou ainda que, justamente por essas particularidades, "la música brasileña, como la cubana, es una de las que más han tenido êxito en el mundo". ${ }^{46}$

Além disso, poderíamos acrescentar que a música popular brasileira e a cubana constituíram-se historicamente como resultado de entrecruzamentos intensos de tradições e referências estrangeiras várias, sendo ambas, nesse sentido, cosmopolitas e diversificadas (talvez mais intensamente que boa parte das músicas populares dos demais países latinoamericanos). Bastante interessante para refletirmos sobre esse caráter de mistura tão fortemente assumido por Cuba e Brasil é o conceito de cultura híbrida, de Néstor García Canclini. ${ }^{47}$ Para esse autor, uma possibilidade de análise e interpretação das identidades culturais latino-americanas seria pensá-las como resultado da configuração de relações complexas, nas quais o "culto" e o "popular" se auto-referem o tempo todo, assim como se mesclam e se confundem o tradicional e o moderno, o local e o universal.

Desse dado (o caráter híbrido da cultura) deriva, a nosso ver, a forte tendência à adoção de uma postura de assimilação das novidades musicais internacionais, característica que aproxima Brasil e Cuba no anseio comum da busca de uma sonoridade universal. Nessa proximidade, entretanto, há um fator a se considerar: enquanto, no Brasil, essa relação musical com o exterior é permeada pela contestação dos padrões estéticos da canção de protesto, em Cuba, há a busca de afirmação - em termos valorativos - e de reconhecimento internacional daquela música popular, que é "de protesto", mas, antes de tudo, é "cubana”, porta-voz da Revolução.

46 CARRASCO, op. cit., p. 40.

47 CACLINI, N. G. Culturas híbridas. Estratégias para entrar e sair da Modernidade. São Paulo: Edusp, 1998. 
Situar a música cubana no plano das vanguardas, equiparando as artes à situação política promissora de Cuba, como "vanguarda política da América Latina" e exemplo de país que conseguiu mudar sua situação política através de mobilização popular, era a intenção existente no projeto de formação do G.E.S. Nesse sentido, tratando de música popular, percebemos que Brasil e Cuba não se consideravam exatamente "parte integrante" da chamada música popular latino-americana (essa dissociação, por questões lingüísticas e culturais, era mais forte no Brasil, naturalmente) e reconheciam-se como movimentos que estavam além da Canção de Protesto tradicional e da Nova Canção, tanto por questões estéticas (caráter cosmopolita) como ideológicas: simbolicamente, os músicos cubanos buscavam um estilo condizente com o fato de já terem passado pela revolução, enquanto os músicos brasileiros, desacreditando na possibilidade do povo e da esquerda em fazê-la, buscavam uma música que apresentasse uma proposta inusitada, radical.

Tornar o popular "universal", atualizado em relação à modernidade musical, parece-nos ser uma tônica comum aos dois movimentos. Assim, se há uma relação paradoxal entre inovação e tradição, tanto em Cuba como no Brasil, parte justamente dela, em termos musicais, a originalidade estética ou, de uma perspectiva menos entusiasmada, a combinação inusitada de elementos que as canções dos dois grupos apresentam.

\section{Referências}

ACOSTA, L. Del tambor al sintetizador. La Habana: Letras Cubanas, 1969. Elige tu, que canto yo. La Habana: Letras Cubanas, 1983.

AGUIRRE, M. Realismo, realismo socialista y la posición cubana. In: ESCALONA, J. F. (Org.). Estética. Selección de Lecturas. La Habana: Pueblo y Educación, 1987.

ARDEVOL, J. Música y revolución. La Habana: Unión/Uneac, 1966.

ATSMA, H.; BURGUIÈRE, A. Marc Bloch aujourd'hui: histoire comparée \& Sciences Sociales. Paris: Ed. de l'École de Hautes Études en Sciences Sociales, 1990. 
CABRERA INFANTE, G. Mea Cuba. São Paulo: Cia. das Letras, 1996.

CANCLINI, N. G. Culturas híbridas. Estratégias para entrar e sair da modernidade. São Paulo: Edusp, 1998.

DÍAZ, C. Sobre la guitarra, la voz. La Habana: Letras Cubanas, 1994.

ERNESTO Che Guevara: política e ideologia. La Habana: Editorial de Ciências Sociales, 1990.

FAVARETTO, C. F. Tropicália: alegoria, alegria. São Paulo: Ateliê, 1996.

GARCIA, W. Bim bom. A contradição sem conflitos em João Gilberto. São Paulo: Paz e Terra, 1999.

GUTIERREZ, F. Silvio Rodríguez, el elegido. Cali: FAID, 1998.

HOBSBAWM, J. E. História do marxismo. Rio de janeiro: Paz e Terra, 1987. v. 9. NAPOLITANO, M. Seguindo a canção: engajamento político e indústria cultural na trajetória da música popular brasileira (1959-1969). São Paulo, 1998. Tese (Doutorado) - Universidade de São Paulo.

OROVIO, H. Diccionario de la música cubana. La Habana: Letras Cubanas, 1992.

PALMER, M. Del bardo que te canta. La Habana: Letras Cubanas, 1988.

PORTUONDO, J. A. Itinerário estético de la Revolución Cubana. La Habana: Letras Cubanas, 1979.

QUINTERO-RIVERA, M. A cor e o som da nação: a idéia de mestiçagem na crítica musical do Caribe hispânico e do Brasil. São Paulo: Annablume/Fapesp, 2000.

SADER, E. A Revolução Cubana. São Paulo: Página Aberta, 1992.

SARTRE, J. P. Que é literatura. São Paulo: Ática, 1993.

SCHWARZ, R. Cultura e política: 1964-1969. In: SCHWARZ, R. O pai de família e outros estudos. Rio de Janeiro: Paz e Terra, 1978.

VILLAÇA, M. Tropicalismo (1967-1969) e Grupo de Experimentación Sonora (1969-1972): engajamento e experimentalismo na canção popular, no Brasil e em Cuba. São Paulo, 2000. Dissertação (Mestrado) - Universidade de São Paulo. 